\title{
Effect of Moisture Content on the Mechanical and Oil Properties of Soursop Seeds
}

\author{
Juliet E. Udoh ${ }^{\mathrm{a}}$, Tajudeen M. A Olayanju ${ }^{\mathrm{a}}$, Olawale U. Dairo ${ }^{\mathrm{a}}$, Akindele F. Alonge ${ }^{\mathrm{b}^{*}}$ \\ ${ }^{a}$ Department of Agricultural Engineering, Federal University of Agriculture, Abeokuta, Ogun State, Nigeria \\ ${ }^{\mathrm{b} D e p a r t m e n t ~ o f ~ A g r i c u l t u r a l ~ a n d ~ F o o d ~ E n g i n e e r i n g, ~ U n i v e r s i t y ~ o f ~ U y o, ~ U y o, ~ N i g e r i a ~}$ \\ akindelealonge@uniuyo.edu.ng
}

A study was carried out on soursop seeds(annona muricata) to investigate the effects of moisture on the mechanical and oil properties of soursop seeds. The moisture levels varied between $5.62 \%, 13.51 \% 17.31 \%$ and $21.39 \%$. The mechanical properties such as force, deformation and at its peak, yield and break points both on the vertical and horizontal axis were carried out and the physiochemical analysis of the oil were analysed. The seed coefficient of static friction was obtained for galvanized steel, plywood, glass fibre and mild steel on an inclined plane apparatus. Oil was extracted from the conditioned seed using Soxhlet extractor and analysed for refractive index, moisture content, density, acid value, peroxide value, flash, fire and smoke points, specific gravity and Free Fatty Acid (FFA) content using standard methods. There were significant $(p<0.05)$ differences in the force at peak, yield and break for seeds at different axis of measurements with the minor axis consistently having the highest values. Highest oil yield of $34.13 \mathrm{~g}$ was obtained at moisture level of $13.51 \%(w . b)$ while the least of $26.82 \mathrm{~g}$ was at $21.39 \%(w . b)$. Oil properties were found to be within the standards of edible oils quality and seeds obtained at moisture content greater than $13 \%$ (w.b) proved to be of best quality than others. The established values of the properties determined in this study would assist engineers and food processors in the design of equipment for its extraction.

\section{Introduction}

The soursop from the Annonaceae family is found to be the most important tropical fruit that contributes much to the wider economic growth of some of the tropical countries such as tropical America, Australia, Africa and Malaysia. Different types of fruits are available for human consumption in the tropics (Emmanuel et al., 2006). According to Rosa et al. (2009), consumption of ready-to-eat fresh-cut fruits and fruit juices has substantially raised over the last few years, mostly due to the increasing demand for low-caloric food products with freshlike characteristics. Researcher has further shown that consumption of fruits and vegetables helps prevent many degenerative diseases such as cardiovascular problems and several cancers (Rico et al., 2007). High levels of vitamin $\mathrm{C}$ keep the urinary tract clean, and vast amounts of fiber improve digestive health. Most fruit juice also contains a number of other nutrients, including potassium, magnesium, thiamin, copper, niacin, folate, iron, and riboflavin. Such fruits include papaya, apricots, avocados, and guava.

The knowledge of mechanical properties is a very important factor that can lead to maximum exploration of the economic potentials of soursop for industrial purposes. This will provide suitable information required for a successful design and development of relevant machines for handling and processing. Research findings have revealed there is a relationship between properties of this crop and the derivative qualities in terms of oil that can be extracted from the seeds. Galkina and Sloan (2008) determined the physical properties of tropical cirrus clouds based on satellite measurements. The main objective of this research work is to determine some engineering properties relevant to processing of soursop seeds and the specific objective is to determine the mechanical properties of soursop seeds (hardness, compression, deformation and the force required to crack) as affected by moisture content also determine the effect of moisture content variation on the oil yield and the proximate characteristics of the expelled oil. 

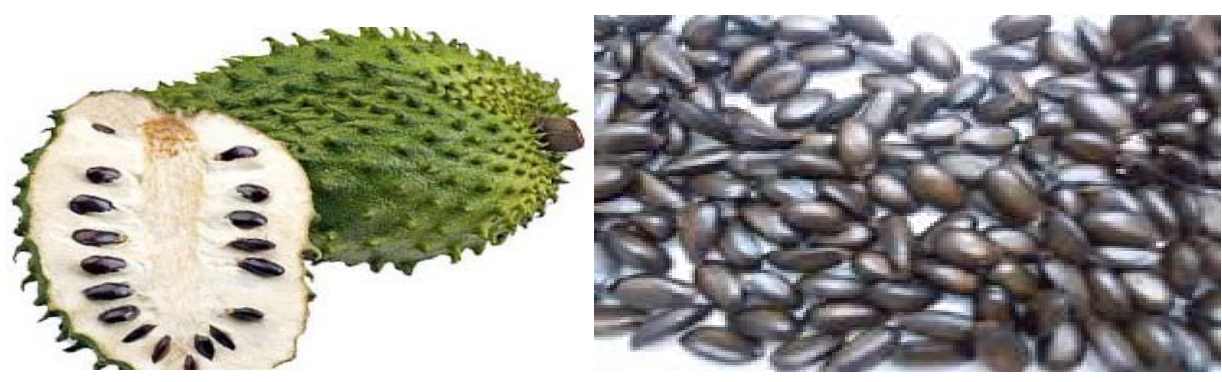

Figure 1: Soursop fruit and seeds

\section{Materials And Methods}

Experiment was carried-out at the Agricultural and Bio-resources Engineering laboratory of the Federal University of Agriculture, Abeokuta, Nigeria. Materials used for this work includes fresh soursop fruits, sharp knife, round bottom flasks, mortar and pestle, spatula, beakers, N-hexane, Soxhlet extractor, Electric oven.

\subsection{Sample and Sample Preparation}

Seeds of soursop were obtained from fresh and physiologically-matured fruits of soursop procured from the National Horticultural Research Institute (NIHORT), Ibadan, Nigeria. A sharp knife was used to peel the soft fruits and cut into smaller sizes, which was gently mashed with mortar and pestle. The mashed sample was then poured in a clean plastic bowl. Clean water of appropriately one litre $(1 \mathrm{~L})$ was added to the mashed sample and thorough hand-mixing was done to ensure maximum seed recovery.

\subsection{Seed Moisture Content Conditioning}

Seeds were conditioned to desired moisture content levels by adding a calculated amount of distilled water to the sample using Eq (1). The sample and added water were then thoroughly mixed. Samples were labelled appropriately and then refrigerated in sealed bags at a temperature of $5^{\circ} \mathrm{C}$ for 7 days. Samples were brought out of the refrigerator 24 hours before use to allow equilibration with room environment and the actual moisture content was determined using standard method of ASABE (2005).

$$
\mathrm{Q}=\frac{W_{i}\left(m_{f}-m_{i}\right)}{100-m_{f}}
$$

where $Q$ is the mass of water to be added $w_{i}$ is the initial mass of the sample $m_{i}$ is the initial moisture content of the sample in $\%$ wet basis $m_{f}$ the final (desired) moisture content in \% wet basis

\subsection{Coefficient of static friction}

The coefficients of static friction of soursop seeds was determined at four different moisture content against four different structural surfaces namely galvanized steel, mild steel, plywood and glass surface.

$$
\mu=\tan \alpha
$$

where $\mu$ is the static coefficient of friction and $\alpha$ is the angle of tilt (degree). The experiment was replicated three times at each moisture content.

\subsection{Angle of Repose}

Angle of repose $\theta$ of the seed was evaluated using a cardboard paper (Paksoy and Aydin, 2004).the diameter $(D)$ and height $(\mathrm{H})$ of the slope was recorded. The angle of repose $(\theta)$ was calculated by using Eq (3)

$$
\theta=\tan ^{-1}\left(\frac{2 H}{D}\right)
$$

where $\mathrm{H}=$ height of cone,

$$
\mathrm{D}=\text { radius of spread of the seeds }
$$




\subsection{Compression Test Loading and Deformation}

Compression tests were performed using micro $500,50 \mathrm{kN}$ capacity Universal Testing Machine (UTM). Randomly selected ten seeds were placed between the compression plates both in the vertical and horizontal axes. The applied forces at bio-yield and oil points and their corresponding deformations for each seed sample were read directly from the force-deformation curve.

\subsection{Determination of Refractive Index}

Refractive Index is the quotient of the sine of the incident angle of light in the air and the sine of the angle of refraction of light in the substance. This was determined using the Abbe's 60/70 refractometer (Bellingham Stanley Ltd).

\subsection{Smoke, Flash and Fire Point}

This was determined by pouring $10 \mathrm{ml}$ volume of the oil in to an evaporation dish, oil sample gives off a blue smoke continuously was noted as the smoke point (Ts). Also the temperature at which the oil started flashing was noted as its flash point (Ts). The fire point which is the temperature at which the oil starts combusting was recorded as (Tc).

\subsection{Free Fatty Acid (FFA) Content Determination of Soursop seed oils}

The Free Fatty Acids (FFA) was obtained using the standard recommended by the Association of Official Analytical chemist (AOAC, 1984), FFA value was then obtained using Eq (4)

$$
F F A=\frac{\operatorname{Titre}(\mathrm{ml}) \times 5.61}{\text { weight of sample used }}
$$

The FFA is usually calculated as oleic acid $(1 \mathrm{ml} 0.1 \mathrm{M}$ sodium hydroxide $=0.0282$ oleic acid), in which case the acid value $=2 \times F F A$

\subsection{Determination of lodine Value}

The iodine value measures the degree of unsaturation in vegetable oils. The iodine value is calculated in line with the AOAC (1986) procedure as

$$
I_{v}=\frac{(b-a) \times 1.269}{w_{t}}
$$

where $I_{v}$ is lodine value

$\mathrm{w}_{\mathrm{t}}$ is the weight of the sample

\section{Results and Discussions}

The result of the coefficient of friction on four surfaces is presented in Table 1 while the effect of moisture content on oil yield is shown in Figure 1. As shown in Table 1, the maximum strain at peak was obtained at moisture level $21.31 \%$ with a value of $281.13 \mathrm{~N}$ while the least strain at peak of $9.70 \mathrm{~N}$ was obtained with seeds at minimum moisture content of $5.62 \%$. Analysis of variance for the mechanical properties showed that there were significant $(p<0.05)$ differences in the force at peak, yield and break for the seeds at different measurement dimensions (i.e the axis of measurement). The difference is also observed for the strain measured at these different axes.

The force at peak obtained from compressive tests on three axial dimensions at three moisture levels is presented in Table 2. Mechanical properties of the seeds were observed to have been significantly affected by moisture levels on applied forces revealed that moisture conditioning had a great influence on the amount of forces required to break the seed, and the optimum required to get oil out of the samples. This was evident in the fact that forces reduced as moisture levels increased among different batches conditioned. However, it appears that it was a reverse situation with the minor axis where force decreased with increased moisture content from 5.62 to $13.51 \%$, increased with moisture of $17.31 \%$ and decreased to a value of $281.13 \mathrm{~N}$ at $21.39 \%$ moisture content. The minor axis values were observed to require the most force for yield, break and at peak when compared to force required with the major and intermediate axes.

The largest strain was also obtained with the minor axes as compared to other axes. The force at peak, yield and break at the same moisture content was highest at the minor axes compared to the two other axes. The maximum and minimum force at peak of $673.68 \mathrm{~N}$ and $43.06 \mathrm{~N}$ respectively were both observe that the minimum moisture content of $5.62 \%$. 
Table 1: Coefficient of friction at various moisture content on selected surfaces

\begin{tabular}{ccccc}
\hline $\begin{array}{l}\text { Moisture } \\
\text { content(\%)(wb) }\end{array}$ & Mild steel & Plywood & $\begin{array}{c}\text { Galvanized } \\
\text { steel }\end{array}$ & Glass \\
\hline 5.62 & $0.47 \pm 0.01^{\mathrm{a}}$ & $0.66 \pm 0.07^{\mathrm{a}}$ & $0.50 \pm 0.01^{\mathrm{a}}$ & $0.47 \pm 0.00^{\mathrm{a}}$ \\
13.51 & $0.57 \pm 0.18^{\mathrm{a}}$ & $0.55 \pm 0.03^{\mathrm{b}}$ & $0.55 \pm 0.01^{\mathrm{a}}$ & $0.52 \pm 0.03^{\mathrm{a}}$ \\
17.31 & $0.52 \pm 0.05^{\mathrm{a}}$ & $0.53 \pm 0.07^{\mathrm{b}}$ & $0.51 \pm 0.44^{\mathrm{a}}$ & $0.49 \pm 0.03^{\mathrm{a}}$ \\
21.39 & $0.53 \pm 0.13^{\mathrm{a}}$ & $0.49 \pm 0.04^{\mathrm{b}}$ & $0.52 \pm 0,01^{\mathrm{a}}$ & $0.50 \pm 0.03^{\mathrm{a}}$ \\
\hline
\end{tabular}

Table 2: The force at peak obtained from compressive tests on three axial dimensions at three moisture levels

\begin{tabular}{llcccccc}
\hline & $\begin{array}{l}\text { Moisture } \\
\text { content(\%) }\end{array}$ & $\begin{array}{c}\text { Force at } \\
\text { peak(N) }\end{array}$ & $\begin{array}{c}\text { Force at } \\
\text { yield(N) }\end{array}$ & $\begin{array}{c}\text { Force at } \\
\text { break(N) }\end{array}$ & $\begin{array}{c}\text { Strain } \\
\text { at peak }\end{array}$ & $\begin{array}{c}\text { Strain at } \\
\text { yield }\end{array}$ & $\begin{array}{c}\text { Strain at } \\
\text { break }\end{array}$ \\
\hline Major & 5.62 & 89.44 & 64.52 & 82.70 & 13.55 & 7.43 & 15.20 \\
& 13.51 & 40.16 & 30.49 & 35.73 & 12.14 & 6.02 & 14.44 \\
& 17.31 & 60.98 & 57.06 & 46.25 & 7.31 & 5.95 & 9.11 \\
Intermediate & 21.39 & 56.91 & 56.88 & 41.10 & 7.22 & 7.18 & 9.00 \\
& 5.62 & 43.06 & 38.6 & 42.01 & 9.70 & 6.51 & 10.31 \\
& 13.51 & 65.30 & 53.16 & 7.68 & 11.77 & 7.68 & 13.92 \\
Minor & 17.31 & 29.40 & 23.47 & 28.17 & 8.58 & 4.89 & 9.07 \\
& 21.39 & 28.21 & 22.09 & 23.73 & 9.93 & 4.97 & 12.49 \\
& 5.62 & 673.68 & 663.28 & 643.03 & 37.44 & 36.77 & 37.69 \\
& 13.51 & 347.69 & 317.8 & 344.62 & 42.34 & 40.41 & 42.21 \\
& 17.31 & 525.51 & 525.51 & 520.80 & 37.70 & 37.69 & 37.95 \\
& 21.39 & 281.13 & 281.16 & 280.89 & 281.13 & 36.32 & 38.05 \\
\hline
\end{tabular}

\subsection{Oil Yield}

It was observed that there was an initial increase in yield with moisture increase until moisture of $13.51 \%$ after which a decline in oil quantity was observed. The highest oil yield was obtained at moisture content level of about $13.51 \%$ while the least was at $21.39 \%$ moisture content. A regression plot of the mean values showed that a polynomial model in form of Eq (1) can be used to describe the oil yield. The coefficient of determination for the model was 0.958 .

$$
y=27.399 x-5.7825 x^{2}+5.7675
$$

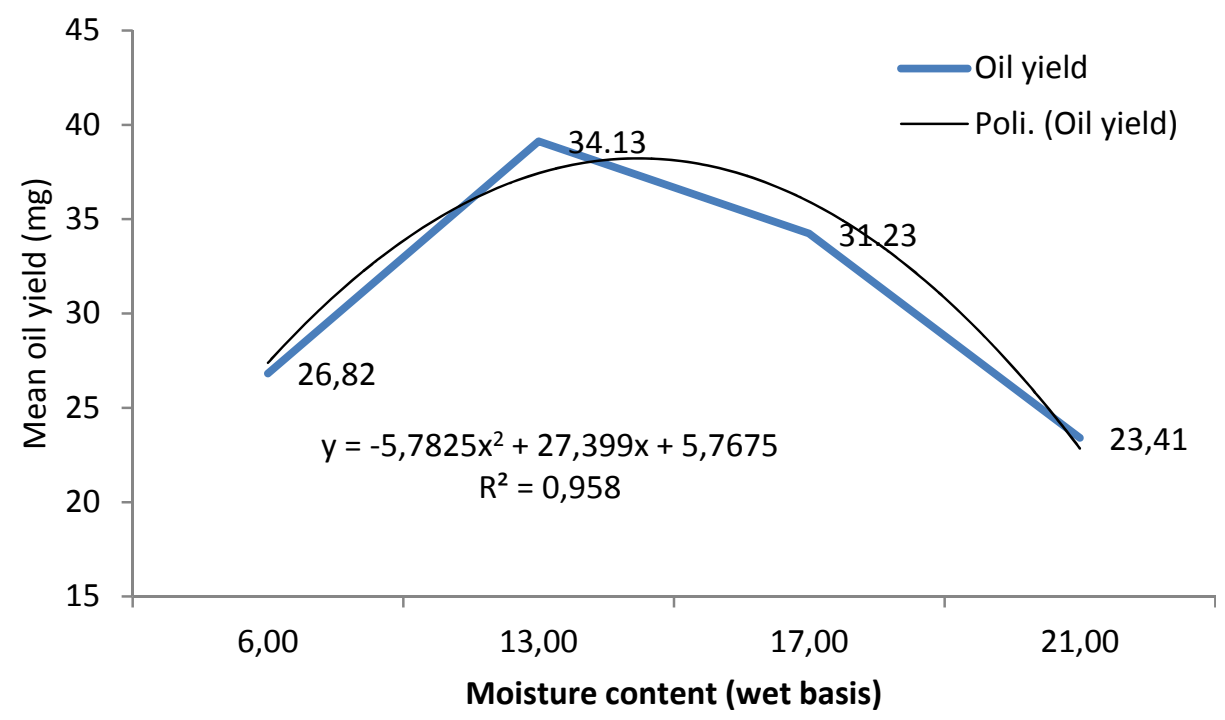

Figure 2: Effect of Moisture Content on Oil yield 


\subsection{Oil Properties}

The values obtained for the various oil properties for Soursop seed oil are as presented in Table 3 . The density values were between 0.75 and $0.91\left(\mathrm{~g} / \mathrm{cm}^{3}\right)$ with specific gravity from 0.76 to 0.93 , and the refractive index was 1.46 at all the moisture levels considered. The fire point was observed to increase with increased moisture content from a value of 56 to $88\left({ }^{\circ} \mathrm{C}\right)$, while fire point decreased with moisture content from a value of 206 to $185\left({ }^{\circ} \mathrm{C}\right)$. Both the acid value and FFA increased with increasing moisture content from 1.04 to $2.64(\mathrm{mg} / \mathrm{g})$ and 3.11 to $5.29(\mathrm{~g} / \mathrm{g})$ respectively. The peroxide value also generally increased from 0.08 to 0.17 with increase in moisture content of the seed. The ANOVA revealed that all the oil properties were significantly different $(p>0.05)$ at different moisture levels except the refractive index which was unaffected by moisture change.

The quantity of oil recovered from the conditioned seeds was higher at low moisture levels than high levels suggesting that there could be an optimum level to which moisture may be present in the seeds for maximum yield; increasing moisture beyond which could mitigate the oil recovery. From the context of this work, highest percentage oil yield was obtained at $13 \%$ implying that high level of oil yield achievable at $8.48 \%$ as reported by Okoro et al. (2013) can likewise be realized at $13 \%$. This therefore follows that the possible moisture range for optimum oil yield is likely to be between $8.48 \%$ and $13.00 \%$ from the result obtained. In terms of quality, fire point was observed to have been influenced by moisture content as increase in moisture content led to increased flash point and vice-versa. In agreement with the report of Alonge (2003), forces at peak, yield and break were highest on the minor axis. Though with soybean seeds, but it was categorically proven that hardness can most-suitably be tested along this (minor) axes in their natural position as noticed in soursop seeds assessed.

Both the acid value and FFA increased with increasing moisture content from 1.04 to $2.64 \mathrm{mg} / \mathrm{g}$ and 3.11 to $5.29 \mathrm{~g} / \mathrm{g}$ respectively. The peroxide value also generally increased from 0.08 to 0.17 with increase in moisture content of the seed which in line with Adepoju et al. (2014). This observation is a true representation of most common edible oils. Finally, soursops unlike every other fruit have seeds having oil rich in properties expected from any other oil seed. Harnessing the potentials through effective design of processing equipment is crucial. Results from this experiment after studying the physical, chemical and mechanical properties of the seeds reveals that all the attributes assessed falls within the range of other oil seeds and if processed on large scale could apart from income generation lead to conversion of waste-to-wealth for human and livestock consumption.

Table 3. Properties of extracted Soursop seed oil at moisture contents of 5.62 to $21.39 \%$ (wb)

\begin{tabular}{|c|c|c|c|c|c|c|c|c|c|}
\hline $\begin{array}{l}\text { Moisture } \\
\text { content } \\
(\% \text { wb) }\end{array}$ & $\begin{array}{l}\text { Density } \\
\left(\mathrm{g} / \mathrm{cm}^{3}\right)\end{array}$ & & $\begin{array}{l}\text { Specific } \\
\text { gravity }\end{array}$ & $\begin{array}{l}\text { Refractive } \\
\text { index }\end{array}$ & $\begin{array}{l}\text { Flash point } \\
{ }^{\circ} \mathrm{C}\end{array}$ & $\begin{array}{l}\text { Fire point } \\
{ }^{\circ} \mathrm{C}\end{array}$ & $\begin{array}{l}\text { Acid value } \\
\mathrm{mg} / \mathrm{g}\end{array}$ & $\begin{array}{l}\text { Free Fatty } \\
\text { Acid } \\
\mathrm{g} / \mathrm{g}\end{array}$ & $\begin{array}{l}\text { Peroxi } \\
\text { de } \\
\text { value }\end{array}$ \\
\hline 6 & $\begin{array}{l}0.91 \\
0.05^{\mathrm{a}}\end{array}$ & \pm & $0.91 \pm 0.07^{a}$ & $1.46 \pm 0.04^{a}$ & $56 \pm 1.63^{d}$ & $206 \pm 2.94^{a}$ & $1.04 \pm 0.05^{\mathrm{C}}$ & $3.11 \pm 2.04^{b}$ & $\begin{array}{l}0.08 \pm \\
0.17^{\mathrm{c}}\end{array}$ \\
\hline 12 & $\begin{array}{l}0.83 \\
0.04^{b}\end{array}$ & \pm & $0.83 \pm 0.05$ & $1.46 \pm 0.00^{a}$ & $68.75 \pm 4.19^{c}$ & $198 \pm 1.63^{b}$ & $1.66 \pm 0.06^{b}$ & $3.33 \pm 0.27^{b}$ & $\begin{array}{l}0.11 \pm \\
0.00^{b}\end{array}$ \\
\hline 17 & $\begin{array}{l}0.75 \\
0.005^{c}\end{array}$ & \pm & $0.76 \pm 0.04^{\mathrm{bc}}$ & $1.46 \pm 0.00^{a}$ & $75.25 \pm 2.63^{b}$ & $192 \pm 2.16^{c}$ & $2.46 \pm 0.39^{a}$ & $4.99 \pm 0.16^{\mathrm{a}}$ & $\begin{array}{l}0.17 \\
0.02^{a}\end{array} \pm$ \\
\hline 21 & $\begin{array}{l}0.93 \\
0.005^{a}\end{array}$ & \pm & $0.93 \pm 0.03^{a}$ & $1.46 \pm 0.06^{a}$ & $88 \pm 0.82^{a}$ & $185 \pm 3.74^{d}$ & $2.64 \pm 0.15^{a}$ & $5.29 \pm 0.08^{a}$ & $\begin{array}{l}0.11 \pm \\
0.005^{b}\end{array}$ \\
\hline Control $^{+}$ & $0.90-0.92$ & & $0.9-1.16$ & $1.467-1.470$ & $60-80$ & $180-200$ & 4.00 & $5.78-7.28$ & NA \\
\hline
\end{tabular}

+ This is the standard value for edible oil according to $\mathrm{FAO} / \mathrm{WHO}$

NA is for data that is not available

Means with same letters are not significantly different from one another

\section{Conclusion}

Studies conducted revealed the following;

i. Coefficient of friction value was the highest on mild steel and least on plywood.

ii. For the mechanical properties of soursop seeds there were significant differences in the force at peak, yield and break for seeds at different axis of measurements with the minor axis always having the highest values.

iii. Deformation was highest in the minor axes as compared to the other axis. The maximum strain at peak was obtained at moisture level $21.31 \%$ with a value of $281.13 \mathrm{~N}$ while the least deformation at peak is $9.70 \mathrm{~N}$ was obtained with seeds at minimum moisture content of $5.62 \%$.

iv. Moisture content has no effect on the refractive index of soursop seed oil at different moisture content of harvest to storage. 
v. Both the acid value and FFA increased with increasing moisture content from 1.04 to $2.64(\mathrm{mg} / \mathrm{g})$ and 3.11 to $5.29(\mathrm{~g} / \mathrm{g})$ respectively.

vi. The seed oil is a good source of edible and industrial oil as shown. It is a good source of fat and oil for animal feedstock as the oil properties were within the standards of edible oils. However, the seeds of moisture content greater than $13 \%$ (w.b.) would be best than the other moisture content.

vii. Processing machine should be develop to produce soursop oil using the obtained data set and also optimize the process factors using the developed machine for the best yield conditions.

viii. Cracking equipment could also be developed using the relationship between mechanical properties and moisture content in the design of such machine.

\section{References}

Alonge A. F (2003). The effect of moisture content on mechanical properties of soybean. [Glycine max (L.) Merr.], Journal of Agricultural Research and Development 2:60-69.

Alonge, A. F. and A. M. Olaniyan, (2006): The Effect of Dilution Volume, Water Temperature and Pressing Time on Oil Yield from Thevetia Kernel during Extraction. Agricultural Mechanization in Asia, Africa and Latin America, Vol.37, No 2, pg. 81-83.

Adepoju, T. F, Olawale, O, Ojediran, O. J and Olatunji, E. M. (2014). Solvent Extraction of Oil from Soursop Oilseeds and Its Quality Characterization, International Journal of Sustainable Energy and Environmental Research, 2014, 3(2):80-89

ASABE (2006). American Society of Agricultural and Biological Engineers Standards. Published by ASABE, St Joseph, Michigan, USA

AOAC (1984). Official Methods of Analysis, 14th Edition. Association of Official Analytical Chemists, Washington, DC, pp. 84-90

Emmanuel S. A., Olurin T. O and Odeyemi G (2006). Studies on the storage stability of soursop (Annona muricata L.) juice. African Journal of Biotechnology Vol. 5 (19), pp. 1808-1812. Available online at http://www.academicjournals.org/AJB ISSN 1684-5315 @ 2006 Academic Journals

Galkina I. L and Sloan J. J (2008). Physical properties of tropical cirrus clouds based on satellite measurements. Chemical Engineering Transactions, volume 16:73-78

Okoro, C. K. Influence of Moisture Content Variation on the Percentage Oil Yield of Soursop (Annona muricata) Seeds. International Journal of Scientific and Engineering Research, Volume 4, Issue 7, July20131288 ISSN 2229-5518 Pp.1288-1292

Paksoy, M. and Aydin, C. 2006. Determining some physical and mechanical properties of pea (Pisum Sativum L.) seeds. Pakistan Journal of Biological Science. 9(1):26-29.

Rosa M. Raybaudi-Massilia, Jonathan Mosqueda-Melgar, Robert Soliva-Fortuny, and Olga Mart'ın-Belloso (2009). Control of Pathogenic and Spoilage Microorganisms in Fresh-cut Fruitsband Fruit Juices by Traditional and Alternative Natural Antimicrobials. Comprehensive review in food science and food safety Vol. 82009.

Rico D, Mart'ın-Diana AB, Barat JM, Barry-Ryan C. 2007. Extending and measuring the quality of fresh-cut fruit and vegetables: a review. Trends Food Science Technology 18:373-86 